\title{
A RELAÇÃO DOS TÉCNICOS DE EDUCAÇÃO DE ADULTOS COM O DISCURSO PEDAGÓGICO OFICIAL: UM CASO A NORTE DE PORTUGAL
}

\author{
Armando Paulo Ferreira Loureiro* \\ Artur Fernando Arêde Correia Cristóvāo**
}

\begin{abstract}
RESUMO: O presente artigo pretende questionar, com base num estudo etnográfico realizado junto de uma equipa técnica de educação de adultos de uma associação de desenvolvimento local do norte de Portugal, a relação que este tipo de técnicos estabelece com o discurso pedagógico oficial proveniente de estruturas de informação que estão na dependência do Estado. Para realizar tal análise recorreu-se, do ponto de vista teórico, ao modelo da estrutura do discurso pedagógico de Basil Bernstein. Os resultados dizem-nos que, neste caso concreto, os técnicos, apesar de terem a sua acção fortemente normativizada, são capazes de estabelecer com o discurso oficial uma relação activa, pois no desenrolar da sua actividade fazem, muitas vezes, usos recontextualizados desse discurso.
\end{abstract}

Palavras-chave: Discurso pedagógico oficial. Usos. Técnicos de educação de adultos.

THE RELATION BETWEEN ADULT EDUCATION AGENTS AND THE OFFICIAL PEDAGOGICAL DisCOURSE: A CASE STUdY IN NORTHERN PORTUGAL

ABSTRACT: Based on an ethnographic study of a team of adult education agents in an association of local development in the North of Portugal, this paper is aimed at studying the relation that these

* Doutor em Sociologia da Educação, professor auxiliar do Departamento de Educação e Psicologia, da Universidade de Trás-os-Montes e Alto Douro (Portugal), e investigador do Centro de Investigação e Intervenção Educativas da Universidade do Porto (Portugal). E-mail: aloureiro@utad.pt

** Doutor em Educação Contínua e Vocacional e professor catedrático do Departamento de Economia, Sociologia e Gestão, da Universidade de Trás-os-Montes e Alto Douro (Portugal).E-mail: acristov@utad.pt 
A relação dos técnicos de educação de adultos com o discurso pedagógico oficial...

agents establish with the official pedagogical discourse emerging from State-dependent information structures. In order to develop this analysis, Basil Bernstein's model of pedagogical discourse structure was used for a theoretical basis. The results have showed that, in this particular case, the agents, in spite of having a strongly normative action, are able to establish an active relation with the official discourse. It can be observed that they often readapt this official discourse in their daily activity.

Key words: Official pedagogical discourse. Uses. Adult education agents.

\section{Introdução}

$\mathcal{E}$

m Portugal a educação de adultos realizada a partir da sociedade civil, nomeadamente a que surge no âmbito das estruturas associativas e outras organizaçóes de desenvolvimento local, tem um dinamismo que não é novo, como nos mostram diversos estudos (Erasmie et al., 1985; Melo, 1988; Lima et al., 1990; Silva, 1990; Lima, 1994; Melo et al., 1998; Canário, 1999). Dinamismo que tem vindo a crescer de forma mais significativa nos últimos anos. Efectivamente, um olhar sobre as actividades de muitas destas organizaçôes demonstra a importância que as acçôes de educação de adultos, sobretudo as de formação profissional, aí assumem. Na descrição que Monteiro (2002, p. 262) realiza das actividades concretizadas por este tipo de instituições em Portugal é evidente este facto, pois as "actividades mais comuns" dessas organizaçôes são precisamente as que dizem respeito às acçôes de ensino e/ ou formação profissional. Outros dados demonstram igualmente o relevo das acçōes de educação de adultos nessas organizaçōes locais (ANIMAR, 1998; Guimarães et al., 2000; Guimarães \& Sancho, 2001; Loureiro, 2006).

Toda esta vivacidade crescente, à qual não é alheia a entrada de Portugal na União Europeia e suas políticas espelhadas nos seus Quadros Comunitários de Apoio, tem-se traduzido em transformaçōes das próprias organizaçóes locais, algumas das quais têm alterado o seu estatuto jurídico e se têm "profissionalizado", passando a integrar novos agentes educativos que até há pouco tempo não existiam ou tinham um significado diminuto no país: educadores sociais, animadores sócio-culturais, formadores, educadores comunitários, técnicos responsáveis pelo diagnóstico, planeamento, concepção, organização, execução 
e avaliação de cursos de educação e formação de adultos, entre outros (Loureiro, 2006).

Julgamos ser relevante pensar o papel destas organizações e dos seus novos actores no campo do desenvolvimento local. Mais precisamente, consideramos ser oportuno pensar esse papel através da relação que vêm estabelecendo com o Estado, sobretudo numa altura em que a educação de adultos vem assumindo, nos últimos anos, alguma relevância política no país, ao contrário do que vinha sendo hábito (Lima, 1994; Melo et al., 1998; Melo et al., 2002; Melo, 2004), devido às intervenções mais recentes do Estado nesta área, com a criação, em 1999 (Decreto-Lei n. 387/99), da Agência Nacional de Educação e Formação de Adultos (ANefa), entretanto substituída pela Direcção Geral de Formação Vocacional (DGFV), ou o lançamento oficial da Iniciativa Novas Oportunidades, por exemplo.

Reflectir sobre essa relação, com base no fornecimento de um discurso pedagógico oficial por parte do Estado e nos usos que nessas organizações locais os seus agentes dele fazem, é a nossa finalidade neste trabalho.

A análise é feita a partir do modelo teórico do discurso pedagógico de Bernstein $(1993,1998)$ e de uma investigação etnográfica realizada junto de uma equipa técnica de educação de adultos que trabalha num Centro de Educação e Formação de uma Associação de Desenvolvimento Local (ADL) do norte de Portugal. A escolha desta equipa resulta de uma primeira e mais extensiva fase da investigação que, com base na análise documental e na realização de entrevistas a uma amostra intencional, realizou o levantamento e a determinação do grau de envolvimento deste tipo de organizaçóes em acçóes de educação de adultos (Loureiro, 2006). Portanto, os dados aqui apresentados dizem respeito apenas à fase etnográfica da pesquisa.

Antes de darmos conta de alguns dos principais resultados a que chegámos, fazemos uma breve referência aos elementos teóricos que mais directamente se relacionam com o objectivo que aqui nos propusemos atingir. Mais precisamente, alude-se ao modelo teórico que mais influência teve na análise dos usos que os técnicos fazem do discurso pedagógico oficial no decorrer da sua acção, à problemática da educação de adultos no contexto do desenvolvimento local, pois é nesse campo que os técnicos estudados realizam a sua actividade, e às agências e 
A relação dos técnicos de educação de adultos com o discurso pedagógico oficial...

agentes de educação de adultos, como forma de melhor situarmos a instituição e a equipa técnica estudada.

A teoria da estrutura do discurso pedagógico oficial de Bernstein

Bernstein $(1993,1998)$ é dos poucos sociólogos da educação que permite pensar a relação que os agentes educativos mantêm com o conhecimento oficial. Este autor desenvolveu uma teoria da estrutura do discurso pedagógico oficial, ou seja, uma teoria acerca da forma como se constrói, regula e distribui o conhecimento oficial pelas instituições educativas. Para tal, elaborou um modelo baseado em três campos interdependentes de construção do discurso: produção, recontextualização e reprodução.

O campo de produção é responsável pela criação do campo intelectual do sistema educativo. O campo recontextualizador tem um papel de charneira entre o campo de produção e o de reprodução do discurso pedagógico. A sua actividade passa pela apropriação dos discursos do campo de produção, transformando-os em discurso pedagógico (Bernstein, 1998). A principal actividade deste campo consiste na construção do quê e do como do discurso pedagógico oficial, ou seja, na construção das categorias, conteúdos e relações a transmitir e na maneira de os transmitir. O campo de reprodução é o lugar da prática pedagógica, no qual se realiza a reprodução do discurso oficial (idem, 1993).

Este modelo foi pensado essencialmente em relação à escola e, no geral, funciona de forma hierárquica desde o campo de produção até ao de reprodução. Todavia, o modelo tem uma dinâmica interna, há "espaços" no desenrolar de todo o processo, há sempre a possibilidade de haver desvios ao seu funcionamento. Por outro lado, ele é aplicável fora do contexto escolar (idem, 1998).

Consideramos estes dois aspectos importantes. É pertinente tentar perceber se e como os actores em contexto de reprodução do discurso descobrem e aproveitam os espaços deixados pelo Estado, ou se criam tais espaços. Efectivamente, a ideia de recontextualização pode ser, na nossa perspectiva, deslocalizada para o campo da prática e, com isso, pode-se perspectivar outro tipo de relação dos actores aí inseridos com o conhecimento, uma relação activa. A abertura analítica do modelo a outros campos educativos, para além do formal, é relevante, pois 
permite a investigação da sua teoria noutros objectos educativos que têm vindo a assumir cada vez maior relevância, como é o caso dos actores e locais de educação não-formal.

\section{A educação de adultos e o desenvolvimento local}

A relação entre educação de adultos e desenvolvimento local tem sido estruturada do ponto de vista teórico, grosso modo, de duas formas complementares: por um lado, vê-se a educação de adultos como um elemento importante de desenvolvimento local; e encaram-se, por outro, os processos de desenvolvimento local (ou pelo menos parte deles) como espaços privilegiados de educação de adultos.

Quintana (1991, 1995) afirma que a educação de adultos é um instrumento de desenvolvimento das comunidades locais e de capacitação dos indivíduos para se promoverem em comunidade. Efectivamente, desde há décadas que esta modalidade de educação é apontada como um factor de desenvolvimento local, nomeadamente do território rural (Lovett, 1982; UNESCO, 1982). Por vezes, essa potencialidade é realçada a partir de tipos de educação de adultos, como a alfabetização (Ribeiro, 1997), a educação básica ou, sobretudo, a formação profissional (Almeida et al., 1994; Jover, 1999; Cristóvão, 2000; Ramalho, 2005).

O desenvolvimento local pode ser entendido como um processo educativo de adultos quando parte, com a participação activa dos autóctones, da situação existente no local, ou seja, das necessidades, dos problemas das populações e dos seus recursos e oportunidades de desenvolvimento. Trata-se de um momento de descoberta e problematização da situação existente, que remete para a experiência passada e conhecimento dos autóctones, para a percepção que se tem dos recursos e também para as aspiraçôes existentes. É, enfim, o momento de conscienciatização, ou seja, de construção de uma visão crítica sobre a realidade presente, de produção de conhecimento.

Este processo tem um valor formativo enorme, pois através dele as pessoas aprendem a conhecer-se melhor, a conhecer a realidade de outra forma e a poder intervir no seu meio com mais capacidade transformativa. A conscienciatização é um processo de troca, de partilha de percepções entre agentes externos e a própria população. É, desta forma, 
A relação dos técnicos de educação de adultos com o discurso pedagógico oficial...

um processo de aprendizagem mútuo, de construção colectiva do conhecimento, no qual participam agentes externos e os interessados nesse processo, passando estes de simples destinatários a participantes do seu próprio desenvolvimento (Freire, 1969, 1971, 1975, 1977; Quintana, 1991; Rogers, 1995; Canário, 1999). É, na essência, um processo de empoderamento.

\section{Agências e agentes de educação de adultos}

Há diversos tipos de instituições que põem em prática a educação de adultos. É das agências que têm objectivos e actividades educativas de adultos claramente definidos que tratamos aqui.

Têm existido vários esforços de sistematização de toda a diversidade que enquadra tais agências. Nós distinguimos três grandes sectores. O sector estatal, que inclui todo o conjunto de instituições centrais, regionais ou locais que se encontram na sua dependência. Em Portugal, é o caso de vários ministérios, do Instituto de Emprego e Formação Profissional (IEFP), da DGFV, entre outras. O sector privado, que inclui o conjunto de instituições que promovem educação de adultos visando o lucro dessas mesmas instituiçỗes: é o caso de alguns centros de informática que proporcionam aulas a adultos. E o sector das organizações não-lucrativas, que engloba as instituições não-governamentais que levam a cabo acções de educação de adultos sem visarem o lucro, entre as quais se incluem, por exemplo, as organizaçôes de desenvolvimento local, regional, rural, urbano, sob designações diversas (associações, fundações, agências, cooperativas etc.). O nosso foco de interesse centra-se nas organizações não-lucrativas, particularmente nas associaçóes de desenvolvimento local, e no relacionamento que estabelecem com o Estado, nomeadamente a partir das instituiçóes que o representam.

Também é diverso e cada vez maior o número de trabalhadores envolvidos nesta área da educação. Apesar disso, avançamos com uma tipologia provisória dos trabalhadores da educação de adultos. A proposta contempla dois aspectos. Por um lado, falamos dos agentes de educação de adultos num sentido espacio-institucional, que nos dá a noção da dimensão geográfica e organizacional em que estes estão envolvidos. Assim, temos: agentes de educação de adultos internacionais, 
onde englobamos aqueles que trabalham em organismos desse tipo, como a UNESCO, por exemplo; agentes de educação de adultos nacionais, isto é, aqueles que trabalham com este tipo de público no Ministério da Educação e serviços centrais, como a DGFV; agentes regionais, constituídos por aqueles que trabalham nos centros de emprego e formação profissional, por exemplo; e os agentes locais, dos quais fazem parte diversos actores, como por exemplo os que nas associações de desenvolvimento local, nos centros de formação, entre outras instituições, são responsáveis e de alguma forma põem em prática as diversas modalidades de educação de adultos.

Por outro lado, tipificamos os trabalhadores da educação de adultos com base nas actividades que desenvolvem. Assim, identificamos: os teóricos da educação de adultos, cuja actividade principal é a de produzir conhecimento teórico sobre esta modalidade de educação, agentes que normalmente estão ligados a universidades, organizações profissionais e também a organismos internacionais; os técnicos da educação de adultos, cuja responsabilidade consiste na realização de um diagnóstico das necessidades educativas, na planificação e concepção de programas de acção, na organização, execução e avaliação dos mesmos em qualquer tipo de organização dedicada à educação de adultos; e os práticos da educação de adultos, dos quais fazem parte aqueles que têm um contacto mais directo com os adultos, seja através da docência propriamente dita (os formadores ou educadores de adultos), ou de outras formas como, por exemplo, aquelas que os animadores consubstanciam através da informação, da promoção de actividades de formação, da animação e conscientização de adultos.

Terminamos a referência aos trabalhadores de educação de adultos, tendo em conta o tipo de intervenção educativa que preconizam, tendo por referência o modelo de conhecimento que praticam. Tal é feito com base na figura do educador de adultos. Pensamos, porém, que as conclusóes tiradas podem ser generalizadas aos restantes trabalhadores desta área.

Jansen (2000), partindo do questionamento do papel da educação de adultos e dos educadores de adultos na actualidade, identifica dois grandes tipos de educadores. Os que baseiam a sua acção na racionalidade técnica, portanto os que agem como especialistas, como portadores de um saber específico que usam na relação com os seus 
A relação dos técnicos de educação de adultos com o discurso pedagógico oficial...

clientes, de forma a resolverem os problemas. Estes são os agentes da "cultura tranquilizante" (idem, p. 47), que é predominante na educação de adultos. O autor pensa que é possível, e desejável, outro tipo de actuação por parte dos educadores de adultos, uma actuação assente no "profissionalismo normativo", ou seja, uma actuação: que questione o porquê da inserção de certos discursos e práticas na educação de adultos e o afastamento de outros (as); que tenha em conta quer as suas experiências contraditórias e multidimensionais, quer as dos educandos; que articule conhecimento técnico com a "construção de biografias com significado", ou seja, que tenha em conta as ambivalências do tempo actual (idem, p. 53- 54).

Leirman (1996), por seu turno, fala-nos de quatro culturas na educação que correspondem a quatro tipos de actores: a cultura racional e cognitiva do especialista; a cultura tecnocrática do engenheiro; a cultura conscientizadora do profeta; e a cultura experiencial e dialógica do comunicador. No primeiro caso, o educador aparece como um especialista portador de informação capaz de resolver os problemas. No segundo, ele aparece como um planificador da acção com criatividade técnica. No terceiro, aparece como agente construtor de significado e mudança com base na reflexão. No último caso, aparece como um especialista na valorização e mediação das experiências vitais dos indivíduos, assentando o seu procedimento no diálogo problematizador dos vários tipos de conhecimento implicados na acção.

São nítidas nestas abordagens as influências de Giroux (1997) e de Apple (1989, 1996, 1997). Vemos nelas também aproximações ao pensamento de Freire $(1975,1977,1997,2001)$ e ao papel do educador no processo de mudança. Segundo Freire (2001), só um trabalhador comprometido socialmente pode ter esse papel, só um actor capaz de actuar e simultaneamente reflectir sobre a realidade é capaz de a transformar, mas isso implica conhecimento sobre ela, um conhecimento fundamentado cientificamente, mas também um conhecimento que articule a técnica e o "humanismo" (idem, p. 22), a teoria e a prática, que articule o conhecimento do trabalhador especializado e o saber daqueles com quem actua.

Quanto a nós, defendemos que, idealmente, todos os trabalhadores da educação de adultos, nomeadamente os que laboram no campo do desenvolvimento local, devem, na sua actuação diária, procurar 
articular conhecimento abstracto e saber contextual (Caria, 2000, 2005; Loureiro, 2006), sendo essa articulação mediada pela reflexão sobre e na acção (Schön, 1992, 1998), pois dessa forma é diminuído o perigo de desfasamento entre modelos teóricos centralmente definidos e a realidade local.

O Estado e a educação de adultos: uma relação mediada pelo uso do discurso pedagógico oficial

A partir deste momento dá-se conta dos resultados a que chegámos com base na investigação etnográfica realizada, sobretudo dá-se conta da forma como os técnicos de educação de adultos da Associação de Desenvolvimento Local (ADL) seleccionada se relacionam com o discurso pedagógico oficial proveniente de estruturas de informação que estão na dependência do Estado. Começamos por fazer uma caracterização sumária daqueles que se constituíram como a nossa unidade de análise e das suas actividades.

\section{A actividade da equipa técnica}

A nossa unidade de análise labora no Centro de Educação e Formação da ADL escolhida e é uma equipa constituída por 6 elementos, 5 dos quais do sexo feminino, com idades entre os 25 e os 45 anos. Todos têm licenciaturas na área da educação ou da sociologia e possuem experiência profissional. $\mathrm{O}$ foco da nossa observação foi a sua actividade.

Identificámos cinco tipos de actividades: técnicas, respeitantes ao diagnóstico, planeamento, concepção, organização, execução e avaliação das acções de educação de adultos; coordenação da equipa técnica, que consiste na organização e avaliação geral do trabalho; gestão, referente ao espaço, recursos materiais, humanos e financeiros do Centro; direcção, relativa a acções que exigem o compromisso formal da associação; e "outras" que enquadram acçôes que não têm a ver directamente com a educação de adultos. A participação dos elementos da equipa nas actividades é diferente, no entanto todos realizam actividades técnicas.

O seu trabalho assume três temporalidades: um ciclo de trabalho diário, ou quase diário, que abrange as acçôes de organização, execução e avaliação da educação de adultos, e as actividade de gestão, 
A relação dos técnicos de educação de adultos com o discurso pedagógico oficial...

coordenação da equipa e de direcção; um ciclo de trabalho anual, centrado nas acções de diagnóstico, planeamento e concepção da educação de adultos a realizar; e um ciclo de trabalho muito variável referente às "outras" actividades.

A maior parte do trabalho é realizada no gabinete técnico. Quase toda a actividade exige o uso diário da escrita por parte dos técnicos e do seu principal instrumento de trabalho, o computador. Essa escrita materializa-se em vários documentos: relatórios, planos de formação, actas de reuniōes, entre outros.

\section{Usos do discurso pedagógico oficial}

O trabalho desta equipa técnica tem uma dupla característica que marca toda a sua actividade e é com base nela que se faz a análise da relação que os seus membros estabelecem com o discurso pedagógico oficial. Referimo-nos ao facto de se tratar de um trabalho altamente normativo, ou seja, um trabalho sujeito a tarefas prescritas por actores externos ao contexto local. A par da normatividade da acção, existem estruturas de informação que balizam o tipo de educação de adultos praticado. Quer dizer, a filosofia das acções a desenvolver está definida à partida por essas estruturas que compóem aquilo a que Bernstein (1993, 1998) chama "campo de recontextualização do discurso pedagógico oficial", que no caso concreto é formado pelos técnicos da DGFV, do Instituto para a Inovação na Formação (INOFOR), do Instituto de Emprego e Formação Profissional (IEFP) e do Programa Operacional de Emprego, Formação e Desenvolvimento Social (POEFDS), que realizam esse trabalho de recontextualização, de transformação dos discursos do campo de produção em discurso pedagógico oficial.

Tal situação materializa-se, por exemplo: na definição prévia da concepção de alguns cursos (cargas horárias, programas etc.); no fornecimento de documentos enquadradores das filosofias e metodologias subjacentes aos tipos de educação de adultos a desenvolver; e no fornecimento de instrumentos de acção, tais como os de mediação do processo de Reconhecimento e Validação de Competências (RVC) adquiridas em contextos diversos de aprendizagem pelos adultos que frequentam os cursos de Educação e Formação de Adultos (EFA), que dão certificação escolar básica até ao $9^{\circ}$ ano e profissional, de forma a 
poderem desenhar-se percursos formativos tendo em conta tais competências. É a este tipo de documentos e instrumentos de actuação que Apple $(1989,1996,1997)$ chama "textos", por meio dos quais se realiza o controlo técnico do trabalho dos professores. Esse material é fornecido por meio de produção escrita, seja pelos documentos tradicionais, seja pela disponibilização da informação nos sites dessas estruturas, e por meio de acções de formação por elas organizadas.

Portanto, seguindo o raciocínio de Bernstein (1993, 1998), a acção da equipa estudada situa-se no campo de reprodução do discurso pedagógico e é enquadrada por um campo de recontextualização desse discurso oficial, que selecciona o quê e o como do discurso construído no campo de produção. De acordo com esse modelo, aos técnicos cabe, essencialmente, reproduzir o discurso recontextualizado no campo intermédio, que é formado por estruturas directamente dependentes do Estado português: o IEFP, o INOFOR, e o POEFDS dependiam na altura da investigação do Ministério de Trabalho e da Solidariedade; a DGFV dependia desse mesmo Ministério e do Ministério da Educação.

A existência deste campo de recontextualização oficial preconiza uma ideia hierarquizada e rígida da relação com o discurso pedagógico oficial, na qual aos técnicos cabe reproduzir esse discurso. Mas será apenas esse o seu papel na relação que mantêm com o discurso oficial? Esta é a pergunta geral à qual procuramos responder e que assim desdobramos: Perante um trabalho tão normativo e perante a existência de um campo de recontextualização do discurso pedagógico oficial, que tipos de usos desse discurso realizam os técnicos? Existe espaço para o uso do discurso oficial que não seja apenas aplicativo e reprodutor das estruturas de informação pertencentes ao campo de recontextualização oficial? Realizam os técnicos, eles próprios, um trabalho de recontextualização através de processos reflexivos assentes numa lógica contextual que lhes permite efectuar usos alternativos do discurso externamente produzido?

Antes de respondermos a estas questóes, esclarecemos que o discurso pedagógico oficial mobilizado pelos técnicos assume três modalidades: discurso conceptual, discurso filosófico e discurso procedimental. O discurso conceptual refere-se ao que é, e nele se enquadra uma série de conceitos (avaliação, parceria, tutor, formador, diagnóstico etc.), de classificaçóes de diferentes fenómenos como, por exemplo, 
A relação dos técnicos de educação de adultos com o discurso pedagógico oficial...

as referentes aos tipos de educação de adultos, e de dados estatísticos aos quais andam associadas categorias que lhe dão sentido de tipo conceptual, por exemplo, dados sobre o analfabetismo. Trata-se de um conhecimento cuja finalidade é definir, classificar.

$\mathrm{O}$ discurso filosófico refere-se a princípios gerais imanentes de um modelo teórico a partir do qual se legitima e justifica a acção. O caso do modelo dos cursos de EFA, que dão certificação escolar e profissional, como vimos, e que remete para um certo entendimento de educação de adultos, foi aquele que permitiu distinguir este sentido do conhecimento. É, portanto, um conhecimento com finalidade legitimadora da acção.

O discurso procedimental, finalmente, diz respeito ao conhecimento cuja finalidade é indicar o que, como, quando e que instrumentos usar para se efectivar uma acção de acordo com os objectivos previstos. Trata-se de prescrições e regras que dirigem a acção. Tais conhecimentos aparecem, muitas vezes, sob a forma de documentos orientadores dessa acção. O documento produzido pelo POEFDs, com um conjunto de orientações relativas à organização dos dossiers técnico-pedagógicos dos cursos, é apenas um exemplo da forte presença desta modalidade do discurso oficial no local observado.

Quanto às questões acima colocadas, clarificamos que para lhes responder procurámos perceber se o discurso pedagógico oficial, quando é mobilizado para a acção, sofre ou não algum tipo de transformação. Isto é, se a finalidade e/ou o conteúdo (entendemos por conteúdo aquilo que compõe as diferentes modalidades do discurso oficial) do discurso vindo do campo de campo de recontextualização eram, de alguma forma, alterados no campo da acção.

À primeira vista, diríamos que apenas há um uso reprodutor do discurso oficial, isto é, um uso meramente aplicativo em que tal discurso é mobilizado do campo de recontextualização oficial, usando os termos de Bernstein (1993, 1998), para o contexto da acção, sem que haja uma modificação da sua finalidade e do seu conteúdo.

Efectivamente, os técnicos fazem um uso reprodutor das três modalidades do discurso oficial identificadas. Consideramos que é feito um uso deste tipo relativamente à modalidade conceptual do discurso quando, por exemplo, usaram as tipologias da educação e formação de adultos, fornecidas pelas estruturas de informação, para classificarem as 
acções desenvolvidas, aquando da construção de um documento que visava responder a imperativos institucionais de ordem externa, como foi o caso da candidatura à acreditação da formação da entidade. Nestes casos, a finalidade do discurso e o seu conteúdo não foram alterados na acção, pois a finalidade de classificar e de definir com que tais enunciados foram construídos mantém-se na acção dos técnicos, pois estes usaram esse conhecimento também para classificar e definir sem terem alterado o seu conteúdo.

$\mathrm{O}$ uso reprodutor da modalidade procedimental do discurso oficial foi evidente. A construção de documentos como os planos de formação, que seguiram as orientações procedimentais vindas do POEFDs, a construção das actas das reuniões das equipas pedagógicas dos cursos $\mathrm{EFA}$, o preenchimento dos formulários relativos à gestão orçamental dos cursos, o preenchimento dos documentos relativos à certificação dos formandos dos cursos EFA, o uso das grelhas de análise do dossier pessoal de RVC dos formandos enviadas pela ANEFA, entre outros, são exemplos dos procedimentos que a equipa técnica executa, mantendo na acção a finalidade e os conteúdos inscritos nas orientações dessas entidades. Isto é, a finalidade do discurso procedimental proveniente das diferentes estruturas de informação não é alterada na acção da equipa técnica, nem o conteúdo, porque eles mantêm a ordem do fazer, a forma de executar a acção, bem como os instrumentos disponibilizados para fazer como se previu que fosse feito.

Também em relação ao discurso filosófico oficial, verificou-se o seu uso reprodutor na acção, quando, por exemplo, durante um processo de descrição/explicação do que era o RVC e de como se organizava o currículo dos cursos EFA, realizado a um formador, um técnico pegou num documento de trabalho fornecido pela ANEFA referente ao referencial de competências-chave e leu-lhe em que princípios se baseava o dito referencial (o da adequação e relevância, o da abertura e flexibilidade, o da articulação horizontal e vertical, e o do equilíbrio), para a partir deles legitimar a acção a ser tida nestas matérias pelo formador.

Portanto, o uso reprodutor do discurso pedagógico oficial é uma realidade inegável. No entanto, uma análise mais pormenorizada dos dados permite-nos afirmar que, para além desse uso, a equipa técnica realiza um uso de tipo recontextualizador, ou seja, um uso que modifica, no contexto da acção, pelo menos uma das dimensões (finalidade 
A relação dos técnicos de educação de adultos com o discurso pedagógico oficial...

e/ou o conteúdo) do discurso proveniente do campo de recontextualização oficial.

Tal situação torna-se possível através de um trabalho técnico-intelectual (Caria, 2003, 2005) realizado pela equipa técnica, que junta reflexividade institucional e reflexividade interactiva, que articula conhecimento abstracto e saber contextual. É quando realizam este tipo de trabalho que nos é possível pensar na ideia da existência de espaços de manobra, ou de brechas (Bernstein, 1993, 1998) que o sistema dá, ou eles próprios criam no desenrolar da sua actividade, na existência de uma autonomia que lhes permite realizar um uso alternativo dos textos (Apple, 1996) fornecidos pelas entidades que enquadram a sua actividade. É este tipo de trabalho que nos leva também para a ideia de que, em contexto, o discurso oficial é, muitas vezes, submetido à epistemologia prática, uma epistemologia de sentido contrário ao da racionalidade técnica (Schön, 1998), em que o conhecimento se transforma em saber, em que o uso do discurso oficial se conjuga com as especificidades locais e saberes contextuais. Vejamos, por meio de alguns casos concretos, como o que acabámos de referir se efectua.

Este tipo de uso foi mais visível na modalidade do discurso onde, precisamente, o grau de orientação da acção é mais notório: o discurso procedimental. Destacamos os usos recontextualizadores efectuados directamente sobre este discurso (instrumentos de actuação) fornecido pelo campo recontextualizador oficial, distinguindo: o uso parcial, o uso invertido da ordem e o uso modificador dos instrumentos.

A forma como é feita, naquele local, a planificação dos temas de vida dos cursos EFA leva-nos para os casos de uso parcial e de ordem invertida dos instrumentos fornecidos. A construção curricular destes cursos tem como pano de fundo temas de vida (democracia, por exemplo) que têm que ser trabalhados em todos os módulos. Para se realizar a planificação desses temas, a DGFV forneceu, através de uma acção de formação, quatro instrumentos de trabalho ("Desenho Global", "Gestão do Referencial de Competências-Chave", "Tema de Vida" e "Actividade Integradora") a serem usados segundo esta ordem. Acontece que os técnicos, apesar de manterem na acção a finalidade do discurso oficial, usam apenas três dos quatro instrumentos, não usam o instrumento "Gestão do Referencial de Competências", e alteram a ordem pela qual os usam, mantendo no fim o "Desenho Global" e, desta forma, alteram o conteúdo do discurso pedagógico oficial. 
Importa salientar a capacidade de selecção e o uso adaptado à realidade local dos materiais fornecidos pela estrutura de informação, importa salientar como na base do uso recontextualizador esteve uma atitude crítica, avaliativa (elementos constituintes do saber-fazer dos técnicos) e simultaneamente justificativa das opçōes tomadas (saber justificativo). Ou seja, os técnicos não usam os instrumentos todos porque, como referiu um deles:

Há duas grelhas que se repetem muito. Essa do desenho global e essa do referencial de competências são muito parecidas, é o mesmo, quer dizer, o tipo de informação que se obtém é o mesmo, por isso para não se estar a duplicar informação não usamos essa do referencial.

Nem os usam pela ordem que lhes foi dito para o fazerem, porque, como salientou uma das técnicas, tal sequência não se adapta à realidade, não é funcional, é rígida e contraria a ideia de participação dos formandos no próprio processo:

As indicações que tivemos foi para fazer a planificação de todos os temas de vida logo no início e, portanto, o primeiro instrumento que tinha que ser preenchido era esse do desenho global. Mas isso torna o processo muito mais rígido e se queremos que os formandos participem, se envolvam também na definição dos temas e na forma de os trabalhar, se queremos isso achamos que seria melhor trabalharmos tema a tema e não fazer tudo logo no início.

Foi essa atitude avaliativa que levou à produção das alterações na forma de fazer a acção em causa, ou seja, que fez precisamente com que a dimensão do saber-fazer respeitante à integração de alterações na prática fosse activada. E como a forma de fazer foi recontextualizada, o saber dizer de quem descreve/explica o procedimento é também ele um uso recontextualizado do procedimento. Este uso tem influência ainda noutra modalidade do saber local, o saber categorial, pois a partir da altura em que todos passam a fazer esse uso recontextualizador todos sabem o que significa naquele local a realização da construção curricular e respectivas planificaçóes dos temas de vida.

Importa realçar que este tipo de actuação, que leva à alteração do discurso pedagógico oficial, foi feito para os adultos participarem no processo, como se pode ver no excerto, e não serem meros receptores de algo construído por outros. É esta lógica recontextualizadora do 
A relação dos técnicos de educação de adultos com o discurso pedagógico oficial...

discurso que permite aos adultos participar no seu próprio desenvolvimento e emancipação.

Quanto aos usos modificadores dos instrumentos fornecidos pelas estruturas de informação, destacamos aqueles que são feitos em alguns dos materiais usados para se realizar o RVC. Refira-se que, em alguns casos, tais modificações resultam da introdução, nesses materiais, de conhecimento abstracto proveniente de outras fontes que não as das estruturas de informação do campo de recontextualização oficial. Tais modificações passam pela alteração oral e/ou escrita de perguntas contidas em tais instrumentos e pelo acrescentar de outras no mesmo tipo de materiais. O objectivo é conseguir-se obter melhor informação relativa às competências dos adultos e fazer com que estes entendam os materiais e expressem as suas competências.

Tal como antes, também agora é da articulação do saber-fazer com o discurso pedagógico oficial que nasce o uso recontextualizador deste. É esse saber que permite a análise crítica acerca do discurso proveniente da estrutura de informação, quer seja através de um trabalho prévio de análise dos materiais do RVC, portanto de um trabalho de reflexão sobre a acção a efectuar, quer seja através de processos de improvisação que levam a que se façam alteraçōes sobre esses materiais na própria altura de os aplicar, fazendo-se uso, nestes casos, da chamada reflexão na acção.

Há um factor de importância fulcral em todo este processo de trabalho técnico-intelectual: a experiência. É ela que faz com que os técnicos passem de aplicadores a recontextualizadores do discurso pedagógico oficial. Ela permite que se faça diferente e de acordo com as especificidades locais, ela permite "ver"; permite passar da necessidade de ter de se verificar, no uso efectivo do instrumento, se uma possível alteração em tal material é realmente relevante, para a capacidade de se antever essa pertinência sem ter que se realizar tal exercício de verificação. Por isso, ela é fundamental para se adquirir outro dos saberes presente nesta equipa técnica: o saber conjecturar.

Assim, saber-fazer e saber conjectural permitem, através de um exercício reflexivo interactivo/contextual que detecta alguma insuficiência nos instrumentos, realizar o tal uso recontextualizador do discurso pedagógico oficial, que passa por duas fases: experimentação (ensaio/teste da alteração no discurso pedagógico oficial) e, caso resulte 
positivamente, generalização do uso recontextualizador desse discurso. Esta forma de proceder é factor de construção do saber local, no qual entra, como se vê, o próprio discurso pedagógico oficial.

Este tipo de uso recontextualizador mantém a finalidade do discurso pedagógico oficial, mas altera o seu conteúdo. Efectivamente, o RVC faz-se naquele local de uma forma que é específica. Assim, porque passou por processos de recontextualização, o RVC tem naquele contexto um significado próprio. Ou seja, não é a sigla que é própria, pois essa é externa àquele local, é a interpretação que localmente fizeram do procedimento para o qual a sigla remete, o que quer dizer que o saber categorial daqueles técnicos relativamente a este processo se refere ao entendimento que todos têm da forma como executam efectivamente o procedimento. Tal como antes, como o discurso procedimental foi recontextualizado, também o saber dizer relativo ao RVC se faz de acordo com o uso feito do discurso oficial.

Uma vez mais, o uso recontextualizador se insere numa lógica emancipadora dos adultos, porque estes, ao perceberem melhor os materiais e ao poderem melhor expressar as suas competências, estão a participar de forma efectiva num processo de descoberta de si próprios que os leva a uma identificação dos seus recursos, o que lhes permitirá ter maior capacidade transformativa de si mesmos.

Em todos os casos até agora referidos, o uso recontextualizador do discurso oficial faz-se sobre o seu conteúdo, ou seja, na acção mantém-se a finalidade do discurso tida no campo de recontextualização oficial. No entanto, julgamos ter identificado ainda outro tipo de uso recontextualizador: aquele que é feito sem alterar o seu conteúdo, mas que é mobilizado para a acção com uma finalidade diferente da que tem no seu campo de recontextualização oficial. Referimo-nos ao caso em que se mobiliza um conceito fazendo dele um uso igual ao que está escrito num documento, portanto sem qualquer alteração do seu conteúdo, para tentar resolver uma situação complexa da acção e, portanto, com uma alteração na acção da finalidade com que foi construído, que é definir.

De acordo com a análise que acabámos de apresentar, pensamos poder afirmar que na acção o saber e o discurso pedagógico oficial se misturam muitas vezes, passando este, quando sujeito a processos de recontextualização, a fazer parte do próprio saber contextual. 
A relação dos técnicos de educação de adultos com o discurso pedagógico oficial...

Efectivamente, a forma como se faz naquele contexto o RVC ou a construção curricular dos cursos EFA, por exemplo, é uma forma particular de realização desses processos que são originalmente gerais e abstractos.

\section{Discussão final}

Os resultados a que chegámos mostram que, mesmo em locais fortemente enquadrados pela regulação do Estado, é possível ter um tipo de acção que não seja apenas reprodutiva das orientações provenientes das suas estruturas. Como refere Giddens (1995, 2000), a estrutura tanto condiciona como possibilita e os actores tanto a reproduzem como a podem alterar. Assim, a estrutura, que são as regras e recursos que se organizam em propriedades dos sistemas sociais, não deve ser vista como determinações totalitárias da acção, porque, por um lado, "não existe uma relação única entre uma actividade e uma regra” e, por outro, "as regras e as práticas só existem em conjunção mútua” (Giddens, 2000, p. 33).

Os técnicos de educação de adultos estudados reproduzem no seu local de actuação o discurso oficial, mas também mantêm com as estruturas de informação dependentes do Estado um relação activa, pois, como vimos, eles fazem usos recontextualizadores do discurso pedagógico oficial que lhes chega. Este tipo de relacionamento baseia-se na capacidade reflexiva dos técnicos e é através dela que articulam o discurso oficial e o seu saber local e, dessa forma, realizam os tais usos recontextualizadores.

Assim, estamos perante uma equipa que é capaz de ter uma atitude crítica face ao discurso oficial, que é capaz de desconstruir os textos oficiais (Apple, 1996), não se limitando a ter uma atitude meramente executora do discurso produzido por outros actores, que desenvolve um tipo de relação com o conhecimento que Giroux (1997) classificaria de intelectual. Uma equipa que, através de processos de reflexão na acção e sobre a acção passada (Schön, 1992, 1998) e futura (Gabiña, 1995), consegue ter uma visão sistémica da realidade em que vive e dos problemas que enfrenta, consegue ter uma capacidade de abstracção necessária para fazer o trabalho técnico-intelectual (Caria, 2003) que se traduz nos tais usos recontextualizadores. Este tipo de trabalho faz-se a partir da experimentação, da discussão e aprendizagem colaborativas e de um forte trabalho em equipa. 
O tipo de actuação destes técnicos possibilita a realização de uma educação de adultos mais próxima de uma filosofia participativa e emancipadora dos adultos. Trata-se de uma prática que se aproxima de um certo entendimento da educação de adultos no campo do desenvolvimento local, âmbito de actuação da equipa técnica estudada, que parte da situação existencial do adulto e do meio que o rodeia, realiza um processo conjunto de conscienciatização, portanto de construção social do conhecimento, que visa tornar capaz a reflexão, a acção e a transformação do adulto e do seu meio a partir dele próprio.

Portanto, os resultados a que chegámos mostram que, mesmo em situações em que as equipas técnicas dependem directa e financeiramente das estruturas centrais que concebem os modelos educação de adultos, é possível ter-se uma acção que tem em conta as especificidades dos locais e dos adultos.

Mas este caso que investigámos em profundidade não quer dizer que seja a regra de actuação deste tipo de equipas que trabalham nas mais diversas Associaçôes de Desenvolvimento Local (ADL). Na verdade, pensamos que, fruto da fortíssima dependência financeira de muitas delas relativamente às entidades que centralmente financiam os programas que lhes permitem realizar as acçôes de educação de adultos, existe um forte risco de desfasamento entre essas acçôes e as reais necessidades dos adultos (Loureiro, 2006). De forma mais concreta, consideramos a seguinte possibilidade: quanto maior for a dependência financeira das instituiçôes e dos técnicos que nelas trabalham, mais probabilidades existem, ou maior será a tendência para se fazer um uso mecânico de determinados sistemas especializados de conhecimento que vão de encontro aos modelos teóricos e políticos que estejam na base dos programas a que concorrem, para assim poderem aceder a tais financiamentos e, com isso, maiores poderão ser as probabilidades de os projectos assim aprovados não corresponderem a reais problemas locais, não responderem às necessidades e expectativas efectivamente sentidas pelos adultos, aparecendo, desta forma, desfasados da realidade. A par disto, se as equipas na fase de execução dos programas prologam o uso reprodutor do discurso oficial, então duplica o risco de desfasamento entre essas acções de educação de adultos e os reais interesses dos adultos e das comunidades locais.

Efectivamente, pensamos que muitas destas instituições da sociedade civil correm o risco de perder uma das suas características essenciais: a 
A relação dos técnicos de educação de adultos com o discurso pedagógico oficial...

autonomia. Isto é fruto da sua dependência financeira a que fizemos referência e da consequente "instrumentalização do dinheiro" (Cohen, 2003, p. 428) a que passam a estar sujeitas.

Recebido em julho de 2007 e aprovado em abril de 2008.

\section{Referências}

ALMEIDA, J. et al. Regioes rurais periféricas: que desenvolvimento? uma experiência no Concelho de Almeida. Lisboa: CAIS; CIES, 1994.

ANIMAR. Guia das iniciativas de desenvolvimento local. Messejana: ANIMAR; PPDR, 1998.

APPLE, M. Maestros y textos: una economía política de las relaciones de clase y de sexo en educación. Barcelona: Paidós; MEC, 1989.

APPLE, M. El conocimiento oficial: la educación en una era conservadora. Barcelona: Paidós, 1996.

APPLE, M. Os professores e o currículo: abordagens sociológicas. Lisboa: Educa, 1997.

BERNSTEIN, B. La estructura del discurso pedagógico. Madrid: Morata, 1993. v.4.

BERNSTEIN, B. Pedagogía, control simbólico e identidad: teoría, investigación y crítica. Madrid: Morata, 1998.

CANÁRIO, R. Educação de adultos: um campo e uma problemática. Lisboa: Educa, 1999.

CARIA, T. A cultura profissional dos professores: o uso do conhecimento em contexto na conjuntura da reforma educativa dos anos 90. Lisboa: Fundação Calouste Gulbenkian, 2000.

CARIA, T. Introdução: a construção etnográfica do conhecimento em ciências sociais; reflexividade e fronteira. In: CARIA, T. (Org.). Experiência etnográfica em ciências sociais. Porto: Afrontamento, 2003. p. 9-20.

CARIA, T. Trabalho e conhecimento profissional-técnico: autonomia, subjectividade e mudança social. In: CARIA, T. (Org.). Saber profissional. Coimbra: Almedina, 2005. p. 17-42. 
COHEN, J. Sociedade civil e globalização: repensando categorias. Dados, Rio de Janeiro, v. 46, n. 3, p. 419-459, 2003.

CRISTÓVÃO, A. Das (des)articulações formação-investigação-extensão. Economia \& Sociologia, Évora, n. 69, p. 149-164, 2000.

ERASMIE, T. et al. Adult education and community development: experiences from programmes launched in the North of Portugal. Linköping: Linköping University, 1985.

FREIRE, P. Educação como prática da liberdade. Rio de Janeiro: Paz \& Terra, 1969.

FREIRE, P. Estensão ou comunicação?: a conscienciatização no meio rural. Rio de Janeiro: Paz \& Terra, 1971.

FREIRE, P. A pedagogia do oprimido. Porto: Afrontamento, 1975.

FREIRE, P. Educação política e conscientização: Lisboa: Sá da Costa, 1977.

FREIRE, P. Pedagogia da esperança: um reencontro com a pedagogia do oprimido. São Paulo: Paz \& Terra, 1997.

FREIRE, P. Educação e mudança. São Paulo: Paz \& Terra, 2001.

GABIÑA, J. El futuro revisitado. Barcelona: Marcombo, 1995.

GIDDENS, A. La constituición de la sociedad. Buenos Aires: Amorroutu, 1995.

GIDDENS, A. A dualidade da estrutura. Oeiras: Celta. 2000.

GIROUX, H. Los profesores como intelectuales: hacia una pedagogía crítica del aprendizaje. Barcelona: Paidós; MEC, 1997.

GUIMARĀES, P. et al. Educação/formação de adultos nas associaçôes: iniciativas popularmente promovidas ou socialmente organizadas? In: Lima, L. (Org.). Educação de adultos: Forum II. Braga: Universidade do Minho; UEA, 2000. p. 169-235.

GUIMARÃES, P.; SANCHO, A. A participação nas associaçōes: novos desafios à educação de adultos. In: Simốes, A. et al. (Org.). Modelos e práticas em educação de adultos. Coimbra: NAPFA, 2001. p. 159-175. 
A relação dos técnicos de educação de adultos com o discurso pedagógico oficial...

JANSEN, T. Dar sentido às transformações sociais. In: LiMA, L. (Org.). Educação de adultos: Forum II. Braga: Universidade do Minho; UEA, 2000. p. 43-56.

JOVER, D. La formación ocupacional: para la inserción, la educación permenente y desarrollo local. Madrid: Popular, 1999.

LEIRMAN, W. Cuatro culturas e educación. Madrid: Cauce, 1996.

LIMA, L. Forum de Educação de Adultos (1987-1993). In: LimA, L. (Org.). Educação de adultos: Forum I. Braga: Universidade do Minho; UEA, 1994, p. 13-26.

LIMA, L. et al. Projecto-Viana (1983-1988): um ensaio de investigação participativa. Braga: Universidade do Minho; UEA, 1990.

LOUREIRO, A. O trabalho, o conhecimento, os saberes $e$ as aprendizagens dos técnicos de educação de adultos numa ONGDL: contribuições etnográficas para uma renovação da Sociologia da Educação. 2006. Tese (Doutoramento) - Departamento de Educação e Psicologia, Universidade de Trás-os-Montes e Alto Douro, Vila Real.

LOVETT, T. Adult education, community development and working class. Nottingham: University of Nottingham, 1982.

MELO, A. Desenvolvimento local como processo educativo. Rede, Faro, n. 2, p. 64-75, 1988.

MELO, A. The absence of an adult education policy as a form of social control and some processes of resistance. In: Lima, L.; GUIMARÃes, P. (Ed.). Perspectives of adult education in Portugal. Braga: Universidade do Minho; UaE, 2004. p. 39-63.

MELO, A. et al. Uma aposta educativa na participação de todos: documento de estratégia para o desenvolvimento da educação de adultos. Lisboa: Gabinete da Secretaria de Estado da Educação e Inovação, 1998.

MELO, A. et al. Novas políticas de educação e formação de adultos: o contexto internacional e a situação portuguesa. Lisboa: ANEFA, 2002.

MONTEIRO, A. Associativismo e novos laços sociais: as iniciativas de desenvolvimento local em Portugal. 2002. Tese (Doutoramento) Departamento de Sociologia, Universidade da Beira Interior, Covilhã. 
QUINTANA, J. Pedagogía comunitaria: perspectivas mundiales de educación de adultos. Madrid: Narcea, 1991.

QUINTANA, J. Experiencias en educación de adultos. In: CARrILlo, J. (Coord.). La educación de adultos: situación actual y perspectivas de futuro. Granada: Fundación Educación y Futuro, 1995. p. 191-198.

RAMALHO, J. Novas conjunturas industriais e participação local em estratégias de desenvolvimento. Dados, Rio de Janeiro, v. 48, n. 3, p. 491-524, 2005.

RIBEIRO, V.M. Alfabetismo funcional: referências conceituais e metodológicas para a pesquisa. Educação \& Sociedade, Campinas, v. 18, n. 60, p. 144-158, dez. 1997.

ROGERS, A. La educación de adultos para el desarrollo. Madrid: Universidad Popular, 1995.

SCHÖN, D. La formción de profesionales reflexivos: hacia un nuevo diseño de la enseñanza y el aprendizage en las profesiones. Barcelona: Paidós, 1992.

SCHÖN, D. El profesional reflexivo: cómo piensan los profesionales quando actúan. Barcelona: Paidós, 1998.

SILVA, A. Educação de adultos, educação para o desenvolvimento. Porto: ASA, 1990.

UNITED NATIONS EDUCATIONAL, SCIENTIFIC AND CULTURAL ORGANISATION (UNESCO). A study on strategies for rural development and the role of education. Paris: UNESCO, 1982. 